\title{
Molecular disruption of DNA polymerase $\beta$ for platinum sensitisation and synthetic lethality in epithelial ovarian cancers
}

\author{
Reem Ali $^{1} \cdot$ Adel Alblihy, ${ }^{1,2}$ Islam M. Miligy, ${ }^{3,4}$ Muslim L. Alabdullah ${ }^{1,3} \cdot$ Mansour Alsaleem $^{3} \cdot$ Michael S. Toss $^{3}$. \\ Mashael Algethami ${ }^{1} \cdot$ Tarek Abdel-Fatah $^{5} \cdot$ Paul Moseley $^{5} \cdot$ Stephen Chan $^{5} \cdot$ Nigel P. Mongan ${ }^{6,7} \cdot$ Satya Narayan $^{8}$. \\ Emad A. Rakha ${ }^{3} \cdot$ Srinivasan Madhusudan $\mathbb{1}^{1,5}$
}

Received: 26 September 2019 / Revised: 4 February 2021 / Accepted: 10 February 2021 / Published online: 5 March 2021

(c) The Author(s) 2021. This article is published with open access

\begin{abstract}
Targeting PARP1 [Poly(ADP-Ribose) Polymerase 1] for synthetic lethality is a new strategy for BRCA germ-line mutated or platinum sensitive ovarian cancers. However, not all patients respond due to intrinsic or acquired resistance to PARP1 inhibitor. Development of alternative synthetic lethality approaches is a high priority. DNA polymerase $\beta$ (Pol $\beta$ ), a critical player in base excision repair (BER), interacts with PARP1 during DNA repair. Here we show that pol $\beta$ deficiency is a predictor of platinum sensitivity in human ovarian tumours. Pol $\beta$ depletion not only increased platinum sensitivity but also reduced invasion, migration and impaired EMT (epithelial to mesenchymal transition) of ovarian cancer cells. Pol $\beta$ small molecular inhibitors (Pamoic acid and NSC666719) were selectively toxic to BRCA2 deficient cells and associated with double-strand breaks (DSB) accumulation, cell cycle arrest and increased apoptosis. Interestingly, PARG [Poly(ADPRibose) Glycohydrolase] inhibitor (PDD00017273) [but not PARP1 inhibitor (Olaparib)] was synthetically lethal in pol $\beta$ deficient cells. Selective toxicity to PDD00017273 was associated with poly (ADP-ribose) accumulation, reduced nicotinamide adenine dinucleotide $\left(\mathrm{NAD}^{+}\right)$level, DSB accumulation, cell cycle arrest and increased apoptosis. In human tumours, pol $\beta$-PARG co-expression adversely impacted survival in patients. Our data provide evidence that pol $\beta$ targeting is a novel strategy and warrants further pharmaceutical development in epithelial ovarian cancers.
\end{abstract}

\section{Introduction}

In BRCA germ-line deficient and platinum sensitive sporadic epithelial ovarian cancers, PARP inhibitor (Niraparib, Olaparib, Rucaparib) maintenance therapy improves

Supplementary information The online version contains supplementary material available at https://doi.org/10.1038/s41388021-01710-y.

Srinivasan Madhusudan

srinivasan.madhusudan@nottingham.ac.uk

1 Translational Oncology, Division of Cancer \& Stem Cells, School of Medicine, University of Nottingham, Nottingham, UK

2 Medical Center, King Fahad Security College (KFSC), Riyadh, Saudi Arabia

3 Academic Pathology, Division of Cancer \& Stem Cells, School of Medicine, University of Nottingham, Nottingham, UK

4 Department of Pathology, Faculty of Medicine, Menoufia University, Menoufia, Egypt progression-free survival (PFS) [1-3]. However, not all patients respond [4] either due to intrinsic resistance or acquired resistance to PARP inhibitors. Therefore, the development of alternative DNA repair targets and synthetic lethality approaches is required.

Base excision repair (BER) is essential for the removal of bases damaged by alkylation, oxidation or deamination $[5,6]$. BER is performed by at least two major sub-pathways: the short-patch pathway (SP-BER) and long-patch pathway (LP-BER) [7]. Both pathways are initiated by a

Department of Oncology, Nottingham University Hospitals, Nottingham, UK

6 Faculty of medicine and Health Sciences, Centre for Cancer Sciences, University of Nottingham, Sutton Bonington Campus, Sutton Bonington, Leicestershire, UK

7 Department of Pharmacology, Weill Cornell Medicine, New York, NY, USA

8 Department of Anatomy and Cell Biology, College of Medicine, University of Florida, Gainesville, FL, USA 
damage-specific DNA glycosylase, which removes the damaged base creating an abasic site. APE1 then cleaves the phosphodiester bond $5^{\prime}$ to the AP site thereby generating a nick with $5^{\prime}$-sugar phosphate (dRP) and $3^{\prime}$ hydroxyl group. DNA polymerase $\beta$ (pol $\beta$ ) adds the first nucleotide to the $3^{\prime}$-end of the incised AP site. Normally, the reaction continues through the short-patch repair pathway where pol $\beta$ removes the $5^{\prime}$-sugar phosphate residue by the process of $\beta$-elimination [8] and DNA ligase III-XRCC1 heterodimer (or DNA ligase I) then completes the repair $[9,10]$. Pol $\beta$-mediated lyase activity is the ratelimiting step in SP-BER. The processing of oxidised AP sites generates a $5^{\prime}$ residue that is resistant to $\beta$-elimination (mediated by pol $\beta$ ) and therefore requires additional DNA synthesis via LP-BER. A role for the polymerase activity of Pol $\beta$ under the coordination of the Rad9-Rad1-Hus1 sliding clamp complex (9-1-1 complex) in LP-BER has also been described [10].

$\operatorname{Pol} \beta$ is a key player in BER [11]. Pol $\beta$ interacts with several components of the BER machinery including XRCC1, ligase III and PARP1 to accomplish its biochemical functions [11]. In the current study, we hypothesised that Pol $\beta$ could promising target in ovarian cancers.

\section{Results}

\section{Polß expression links to aggressive epithelial ovarian cancers}

A total of 379 tumours were suitable for analysis of nuclear expression of pol $\beta$. 217/379 (57.3\%) tumours were low for pol $\beta$ and 132/379 (42.7\%) of tumours were high in pol $\beta$ expression (Fig. 1A). Low pol $\beta$ expression was more common in mucinous cystadenocarcinoma, endometrioid and clear cell carcinomas $(p=0.001)$. Whereas, high pol $\beta$ expression was seen in sub-optimally debulked $(p=0.023)$ (Supplementary Table 1). On the other hand, FIGO stage I disease were more common in tumours with low pol $\beta$ expression $(p=0.003)$. Platinum resistance was more common in tumours with high pol $\beta$ expression although it did not reach significance $(p=$ 0.076). High $\operatorname{pol} \beta$ expression was associated with poor PFS $(p=0.020)$ (Fig. 1B) and poor overall survival (OS) $(p=0.029)$ (Supplementary Fig. S1A). At the transcriptional level, similarly, high pol $\beta$ mRNA expression was associated with poor PFS and OS in both the test and validation cohort 1 (all $p$ values $<0.05$ ) (Supplementary Fig. S1). In the cancer genome atlas (TCGA) cohort (Validation cohort 2), high pol $\beta$ mRNA expression was associated with poor PFS (Fig. 1C). Clinical data suggest that high pol $\beta$ is a marker of adverse phenotype. We proceeded to pre-clinical studies.

\section{Pol $\beta$ localises to the nucleus after platinum treatment in ovarian cancer cells}

We chose A2780 (platinum sensitive) and A2780cis (platinum resistant) ovarian cancer cell lines for initial preclinical studies [12] (Fig. 1D). To evaluate for alterations in sub-cellular localisation of pol $\beta$ upon cisplatin treatment, we generated nuclear and cytoplasmic extracts at baseline and following $48 \mathrm{~h}$ cisplatin therapy. We observed a significant accumulation of pol $\beta$ protein in the nucleus in A2780cis cells compared A2780 cells (Fig. 1E) and (Supplementary Fig. S2A). There was no alteration in cytoplasmic level of pol $\beta$ protein in A2780 or A2780cis cells (Fig. 1E) and (Supplementary Fig. S2A). For further validation, we monitored pol $\beta$ sub-cellular localisation upon cisplatin treatment using immunofluorescence assay at 24 and $48 \mathrm{~h}$. As shown in Supplementary Fig. S2B, C, we observed substantial nuclear accumulation of $\operatorname{pol} \beta$ after $48 \mathrm{~h}$ of cisplatin treatment in A2780cis cells compared to A2780 cells. The data suggest that alterations in sub-cellular localisation of pol $\beta$ after platinum therapy may influence sensitivity.

\section{Bioinformatics analyses of the pol $\beta$ interactome}

As pol $\beta$ mutants [13] have been reported previously to influence biochemical function and platinum sensitivity, we performed next generation exome sequencing and used the variant effect predictor tool [14] to identify genetic variants in platinum sensitive (A2780, PEO1) and platinum resistant (A2780cis, PEO4) cells (manuscript in preparation). We did not observe any pol $\beta$ variants in A2780, A2780cis, PEO1 and PEO4 cells. While variants affecting pol $\beta$ functionally associated genes were not statistically enriched in platinum-resistant cell lines, given the crucial role of $\operatorname{pol} \beta$ as a mediator of platinum resistance, we next examined loci encoding pol $\beta$-interacting proteins, as defined in the BioGRID database [15] (Supplementary Fig. S3A). Among these pol $\beta$ interacting proteins, we identified coding variants affecting $L I G 3, X R C C 3$, WRN; synonymous variants affecting $E P 300, U N G, X P C$ and noncoding variants affecting the APEXI, APTX, BCKDHA, BCKDHB, HUS1, KTN1, NEIL1, RAD9A, SRPK2, SRPK2, STUB1, TDP1, TLE1, TPP2, XPC, CRBN, TAF1D loci in platinum resistant $\mathrm{A} 2780$ cis and $\mathrm{PEO} 4$ cells compared to platinum sensitive A2780 and PEO1 cells (Supplemental Table 2). These include novel variants in EP300, HUS1, $K T N 1, U N G, W R N, X R C C 3$ and $X P C$. Taken together, the data suggest that $\operatorname{pol} \beta$ and variants affecting the $\operatorname{pol} \beta$ functional interactome may contribute to platinum resistance either directly or indirectly through interactions with other factors involved in processing platinum induced DNA damage. 

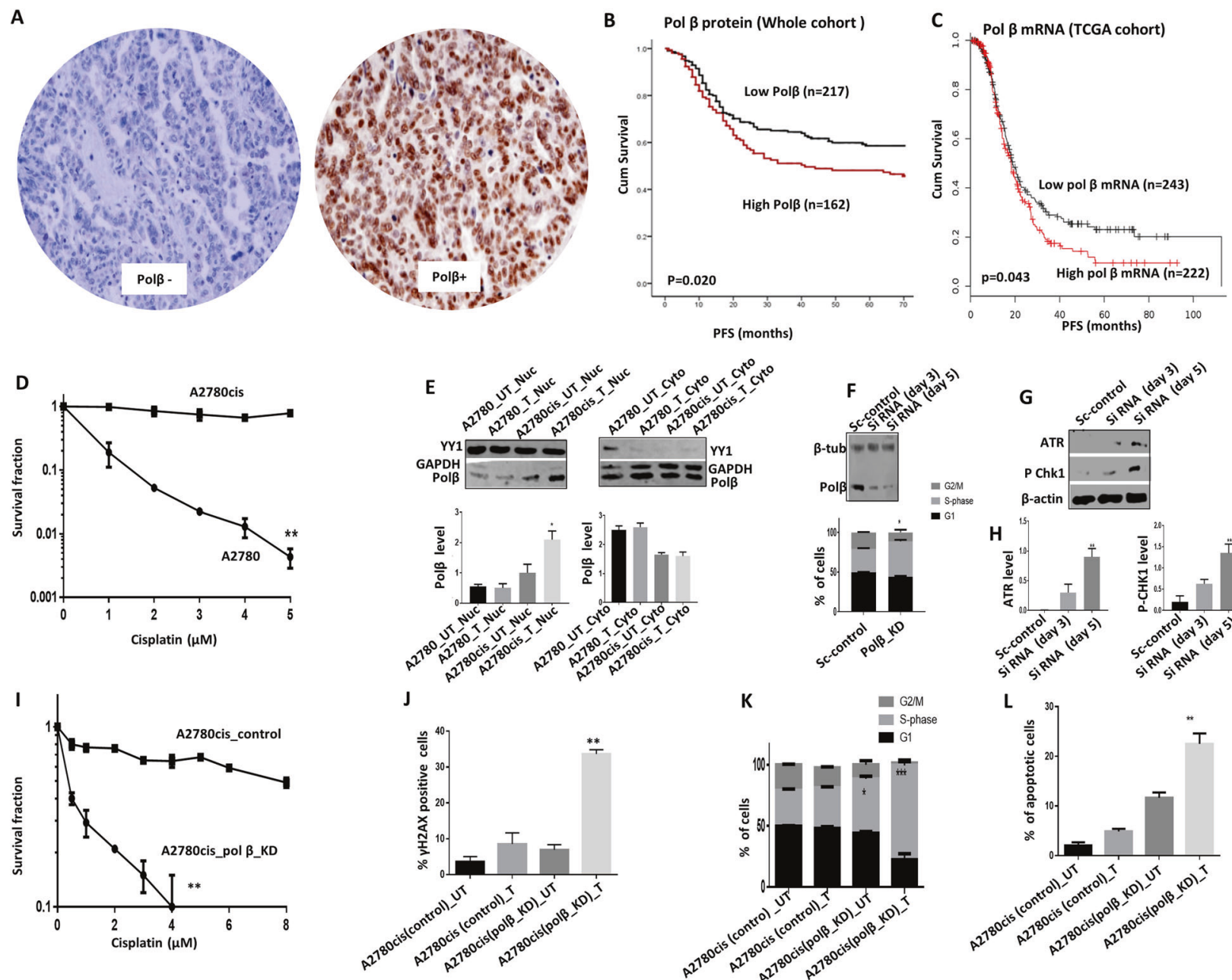

Fig. 1 High Pol $\beta$ expression is linked to aggressive ovarian cancers. A Immunohistochemical expression of $\operatorname{Pol} \beta$ in ovarian cancers. B Kaplan-Meier curve for overall survival in: whole cohort. C Kaplan-Meier curve for Pol $\beta$ mRNA expression. D Cisplatin sensitivity by clonogenic survival assay in A2780 and A2780cis. E Pol $\beta$ nuclear and cytoplasmic extracts in A2780 and A2780cis treated with $5 \mu \mathrm{M}$ cisplatin. Lysates collected $48 \mathrm{~h}$ post treatment. F Pol $\beta$ siRNA knock down in A2780cis cells. Cell cycle analysis for A2780cis control and Pol $\beta \_$KD cells is shown here, G ATR and p-CHK1 protein expression in A2780cis Polß_KD cells. H Quantification of ATR and p-CHK1 by western blot. I Cisplatin sensitivity by clonogenic survival assay in A2780cis cells control and A2780cis_Pol $\beta$ KD cells.

\section{Pol $\beta$ depletion increases platinum sensitivity}

BER may operate predominantly during G1 phase of the cell cycle [10]. Moreover, a BER complex (consisting of pol $\beta$, APE1, UNG2 and XRCC1) was shown to physically associate with MCM7 suggesting that BER may also operate at sites of base damage and single-strand breaks occurring at replication forks [16]. In addition, pol $\beta$ activity may also be prominent during the S-phase of the cell cycle [17]. We therefore generated transient knockdowns (KD) of pol $\beta$ in A2780cis cells using siRNAs (Fig. 1F, Supplementary Fig. S4A) and evaluated cell cycle progression in

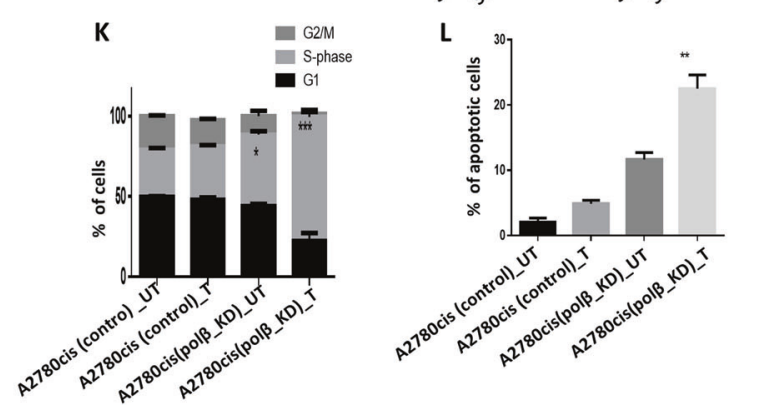

J Quantification of $\gamma \mathrm{H} 2 \mathrm{AX}$ positive cells by flow cytometry in A2780cis cells control and Pol $\beta$ knnock down treated with $5 \mu \mathrm{M}$ cisplatin for $24 \mathrm{~h}$. K Cell cycle analysis by flow cytometry in A2780cis cells control and Pol $\beta$ _knockdown treated with $5 \mu \mathrm{M}$ cisplatin. L AnnexinV analysis for apoptotic cells in A2780cis cells control and Pol $\beta$ knock down treated with $5 \mu \mathrm{M}$ cisplatin. For Flow cytometry cells were seeded and transfected with scrambled control or Pol $\beta$ siRNA. At day 3 controls and knockdown cells were re platted in sixwell plates overnight and treated with $5 \mu \mathrm{M}$ cisplatin and analyzed by flow cytometry on day 5. Transfection efficiency was confirmed by western blotting. Figures are representative of three or more independent experiments.

control and pol $\beta$ _KD cells. Compared to control cells, we observed significant $S$-phase arrest in pol $\beta \_K D$ cells (Fig. 1F) which was associated with accumulation of ATR and pChk $1^{\text {ser } 345}$ (Fig. 1G, H) and (Supplementary Fig. S4B, $\mathrm{C})$, a feature that would be consistent with replication stress in A2780cis polB_KD cells. In clonogenic assays, Pol $\beta$ KD_A2780cis cells (transient KD generated using siRNA) were strikingly sensitive to platinum therapy (Fig. 1I). We also confirmed this observation using another siRNA construct which also showed robust Pol $\beta \_K D$ and also lead to platinum sensitisation (Supplementary Fig. S4D, E). Pol $\beta \_K D$ was associated with double-strand break 

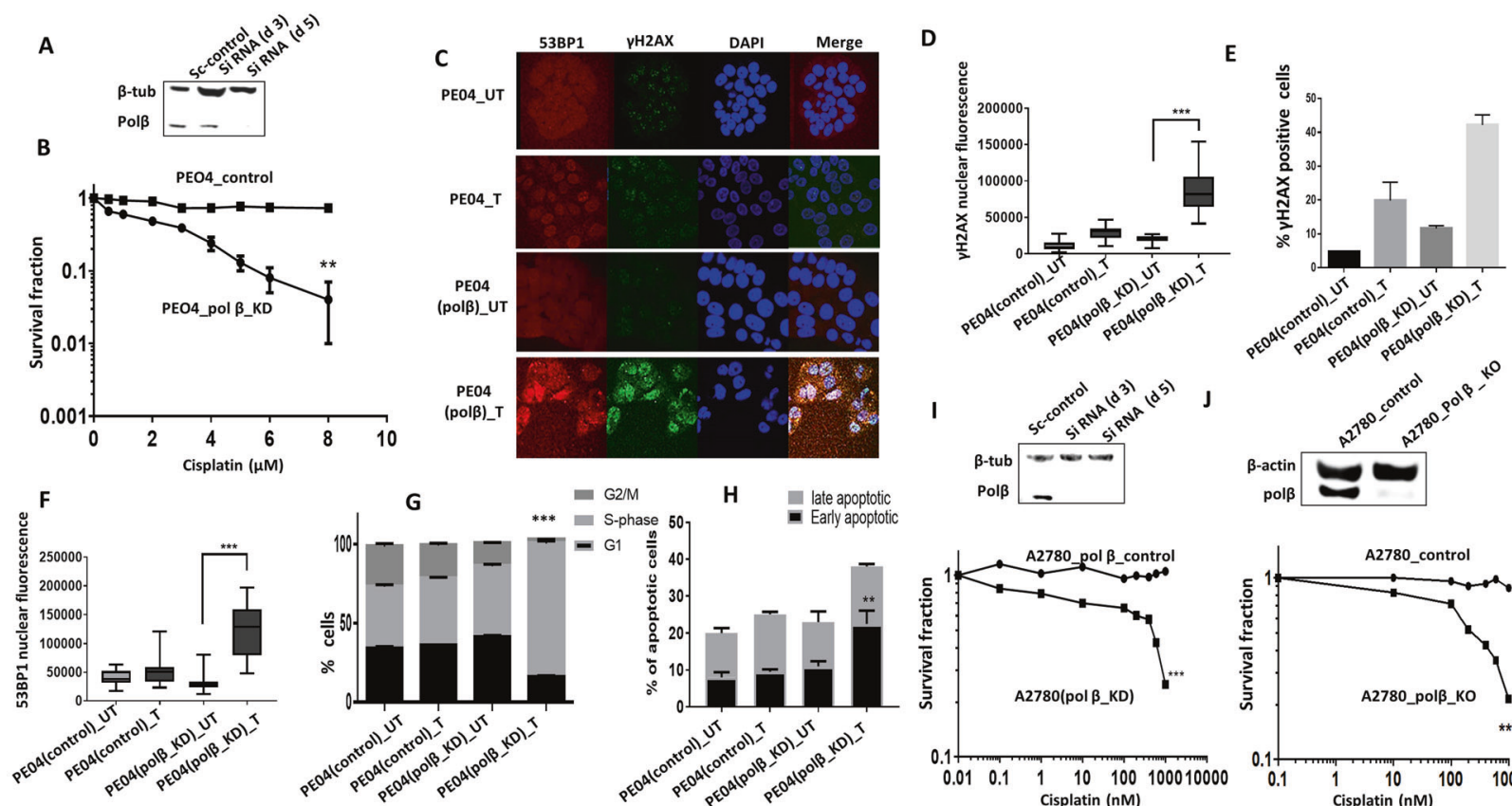

$\begin{array}{lll}\text { G2/M } & \mathrm{H} & \text { late apoptotic } \\ \text { S-phase } & 50 & \text { Early apoptotic }\end{array}$

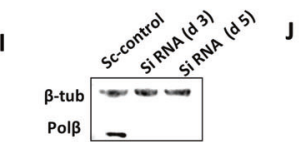

K
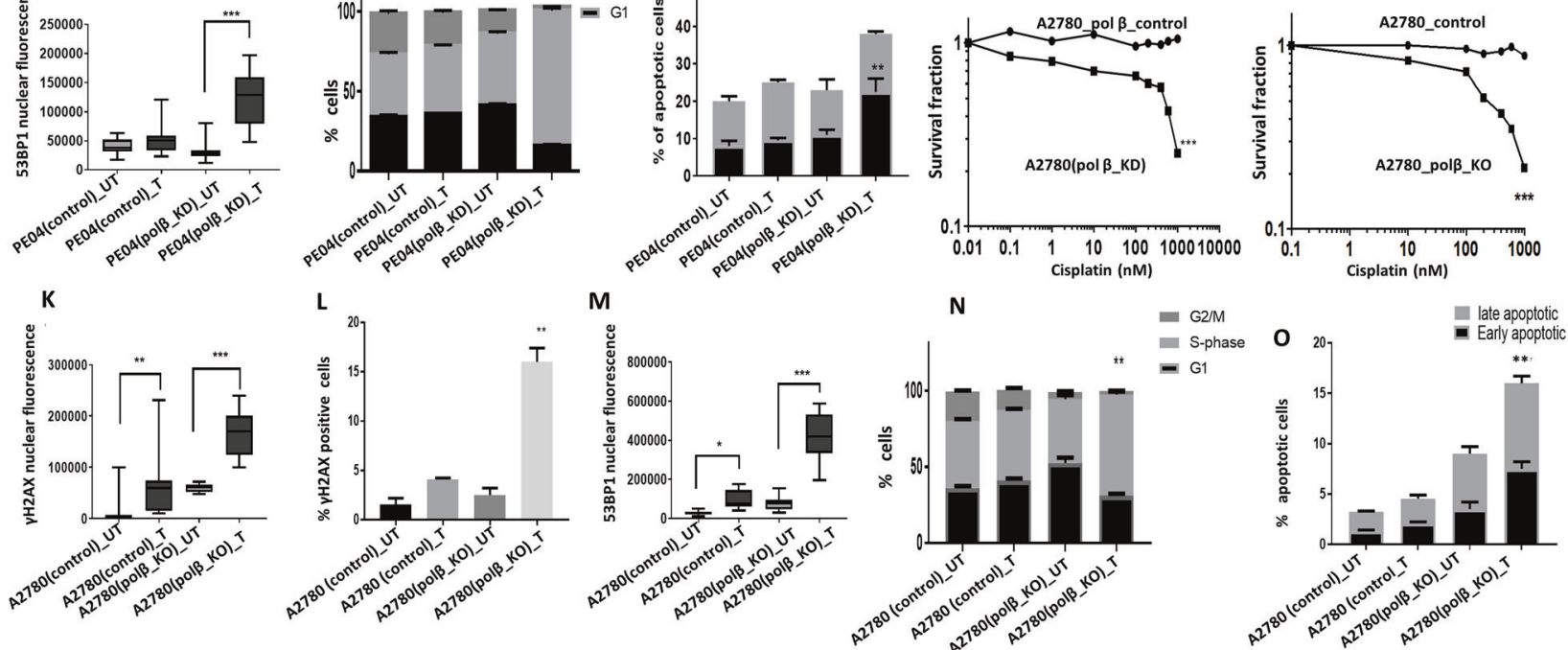

Fig. 2 Pol $\beta$ depletion in ovarian cancer cell lines. A Pol $\beta$ siRNA transfection in PEO4 cells. B Cisplatin sensitivity by clonogenic survival assay in PEO4 scrambled control transfected cells and PEO4 Pol $\beta$ _knockdown. PEO4 scrambled control and PEO4_Pol $\beta$ knockdown cells were treated with $5 \mu \mathrm{M}$ cisplatin and on day 5 cells were analyzed by flow cytometry. C Representative photomicrographic images for immunofluorescence staining of $\gamma \mathrm{H} 2 \mathrm{AX}$ and 53BP1 in PEO4 scrambled control and pol $\beta$ knockdown cells treated with $5 \mu \mathrm{M}$ cisplatin. D Quantification of $\gamma \mathrm{H} 2 \mathrm{AX}$ nuclear fluorescence by ImageJ software. E Quantification of $\gamma \mathrm{H} 2 \mathrm{AX}$ positive cells by flow cytometry. F Quantification of 53BP1 nuclear fluorescence by ImageJ software. G Cell cycle analysis by flow cytometry. $\mathbf{H}$ Annexin V analysis by flow cytometry. I Pol $\beta$ siRNA transfection in A2780 cells and Cisplatin sensitivity by clonogenic survival assay in A2780 scrambled

(DSB) accumulation (Fig. 1J), S-phase cell cycle arrest (Fig. 1K) and apoptosis (Fig. 1L). We then tested in another platinum resistant PEO4 ovarian cancer cells. As expected, pol $\beta$ depletion (Fig. 2A) and (Supplementary Fig. S4F) increased platinum sensitivity (Fig. 2B) was associated with increased $\gamma \mathrm{H} 2 \mathrm{AX}$ nuclear foci (Figs. 2C-E), 53BP1 foci accumulation (Fig. 2F) S-Phase arrest (Fig. 2G) and apoptotic cells (Fig. 2H). In platinum sensitive A2780 cells treated with very low doses of cisplatin (nanomolar range), again pol $\beta$ depletion by SiRNA (Fig. 2I) and (Supplementary Fig. 4G) or with CRISPR-cas9 (Fig. 2J) resulted in control and Pol $\beta \_K n o c k d o w n$ cells. J Pol $\beta$ knock out by CRISPRCas9 in A2780 cells and Cisplatin sensitivity by clonogenic survival assay in A2780 control and Pol $\beta$ KKnock out cells. K Quantification of $\gamma \mathrm{H} 2 \mathrm{AX}$ nuclear fluorescence by ImageJ software. A2780 control and A2780 Pol $\beta$ knock out cells were treated with $1 \mu \mathrm{M}$ cisplatin and analyzed by Immunofluorescence or flow cytometry on day 5 . L Quantification of $\gamma \mathrm{H} 2 \mathrm{AX}$ positive cells by flow cytometry. M Quantification of 53BP1 nuclear fluorescence by ImageJ software. $\mathbf{N}$ Cell cycle analysis by flow cytometry. $\mathbf{O}$ Annexin V analysis by flow cytometry. A2780 control and Polß_KO cells were plated overnight and treated with $1 \mu \mathrm{M}$ cisplatin for $24 \mathrm{~h}$. After incubation, cells were collected and stained as per the flow cytometry protocol detailed in the methods. Figures are representative of three or more independent experiments.

increased platinum sensitivity. We confirmed this result using two siRNA constructs which showed robust pol $\beta$ knock down and similarly lead to platinum sensitisation (Supplementary Fig. S4H, I). Pol $\beta$ depletion increased $\gamma \mathrm{H} 2 \mathrm{AX}$ nuclear foci accumulation (Fig. 2K, L) and (Supplementary Fig. S5A), 53BP1 nuclear foci accumulation (Fig. 2M), S-phase arrest (Fig. 2N) and apoptotic cells (Fig. 2O).

We have tested another Isogeneic ovarian cancer cell line model. PEO1, which is BRCA2 deficient, is a platinum sensitive ovarian cancer cell line. We have recently 

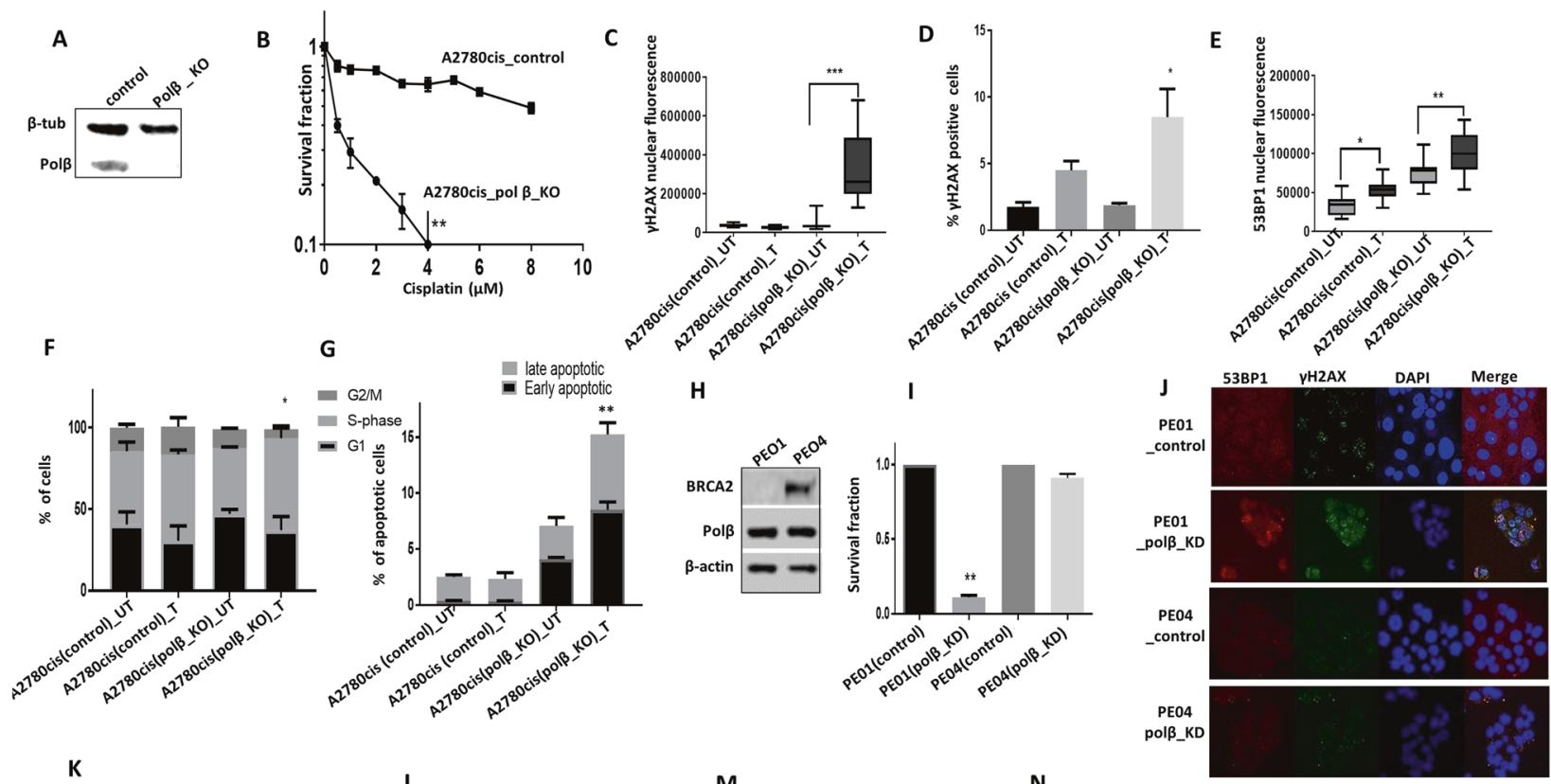

K

$\mathbf{L}$

M
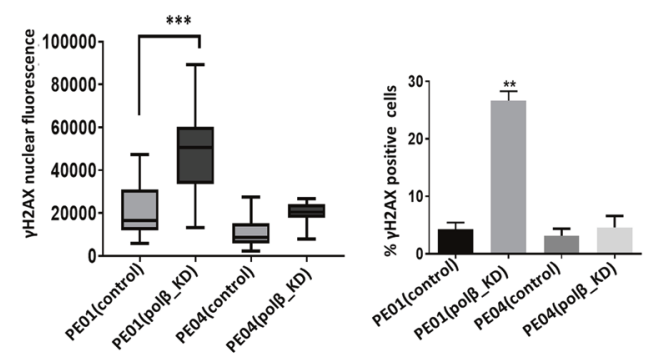

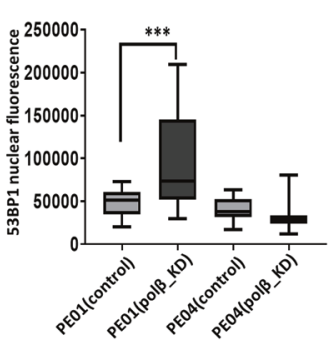

N

$\mathbf{0}$
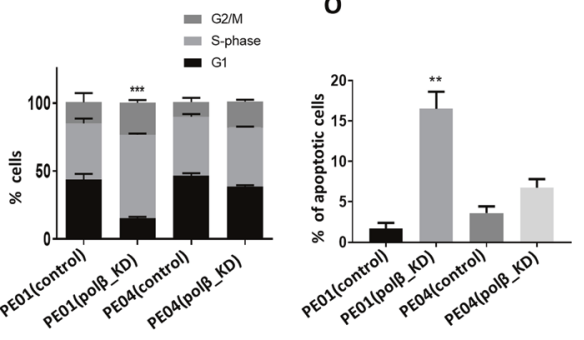

Fig. 3 Pol $\beta$ knock out increases platinum sensitivity. A Pol $\beta$ CRISPR_knockout in A2780cis cells. B Cisplatin sensitivity in A2780cis control and Pol $\beta$-knockout cells. C Quantification of $\gamma \mathrm{H} 2 \mathrm{AX}$ nuclear fluorescence by ImageJ software. D Quantification of $\gamma \mathrm{H} 2 \mathrm{AX}$ positive cells by flow cytometry. E Quantification of 53BP1 nuclear fluorescence by imageJ software. F Cell cycle analysis by flow cytometry. G Annexin V analysis by flow cytometry. For A2780cis control and Polß_knockout cells, Cells were treated with $5 \mu \mathrm{M}$ cisplatin for $24 \mathrm{~h}$ and analyzed by flow cytometry or cells were plated on coverslips overnight and treated with $5 \mu \mathrm{M}$ cisplatin for $24 \mathrm{~h}$. Cells were then fixed and stained for immunofluorescence as detailed in the methods. All figures are representative of three or more experiments.

generated a platinum resistant and PARP inhibitor (Olaparib) resistant cell line (PEO1R) from PEO1 cells. PEO1R was generated by chronic exposure to an inhibitor of MRE11 (mirin) over 6 months (Alblihy et al. manuscript submitted). As shown in Supplementary Fig. S5B, PEO1R is resistant to cisplatin treatment compared to PEO1 (Supplementary Fig. S5B). Interestingly, Pol $\beta$ knockdown in PEO1R cells significantly increases sensitivity to cisplatin (Supplementary Fig. S5B).

We then generated A2780cis pol $\beta$-knockout (KO) cells using CRISPR-Cas-9 methodology (Fig. 3A) and (Supplementary Fig. S5C). As shown in Fig. 3B, polB_KO strikingly increased sensitivity to platinum which was associated increased nuclear $\gamma \mathrm{H} 2 \mathrm{AX}$ nuclear foci accumulation
H BRCA2 and pol $\beta$ expression by western blot in PEO1 and PEO4 cells. I Survival fraction in PEO1 and PEO4 control and Pol $\beta_{-}$knockdown cells. J Representative photomicrographic images of PEO1 and PEO4 control and Pol $\beta$ _knockdown cells. K Quantification of $\gamma \mathrm{H} 2 \mathrm{AX}$ nuclear fluorescence by ImageJ software. $\mathbf{L} \gamma \mathrm{H} 2 \mathrm{AX}$ positive cells analysis by flow cytometry. M Quantification of 53BP1 nuclear fluorescence by ImageJ software. N Cell cycle analysis by flow cytometry. $\mathbf{O}$ Annexin V analysis by flow cytometry. PEO1 and PEO4 control and Pol $\beta$ knockdown cells were transfected with Pol $\beta$ SiRNA; on day 4 cells were plated in six-well plates overnight and analyzed by flow cytometry on day 5. Figures are representative of three or more experiments.

(Fig. 3C, D) and (Supplementary Fig. S5D), 53BP1 foci accumulation (Fig. 3E), S-phase arrest (Fig. 3F) and accumulation of apoptotic cells (Fig. 3G). As platinum treatment can induce the generation of free-radicals in cells and cause oxidative DNA base damage, we also explored if the sensitivity to cisplatin could be altered upon antioxidant treatment. To address this hypothesis, we pre-treated cells with curcumin (antioxidant) for $24 \mathrm{~h}$ followed by cisplatin treatment. Pol $\beta$ deficient cells remained sensitive to platinum therapy (Supplementary Fig. S6A). We then tested another DNA cross-linker Mitomycin C. We again observed that pol $\beta \mathrm{KO}$ cells were also sensitive to mitomycin $\mathrm{C}$ treatment (Supplementary Fig. S6B). Together, the data provide evidence that $\operatorname{pol} \beta$ is a predictor of platinum sensitivity. 


\section{A role for Pol $\beta$ in the regulation of invasion, migration and EMT}

There is also emerging evidence for the role of epithelial to mesenchymal transition (EMT) in ovarian cancer chemotherapy resistance [18]. To evaluate if $\operatorname{pol} \beta$ can also influence the aggressive behaviour of ovarian cancer we proceeded to investigate invasion, migration and EMT in control and pol $\beta \_K O$ ovarian cancer cell lines. Pol $\beta \_K O$ in A2780 and in A2780cis cells significantly reduced invasion (Supplementary Fig. S7A). Given the well-defined roles of E-cadherin [19], N-cadherin [20], TGF $\beta$ [21] and MMP-9 [22] in invasion and EMT regulation, we evaluated if pol $\beta$ could influence the expression of these key EMT markers in ovarian cancer cells. As shown in Supplementary Fig. S7B-D there was a clear induction of E-cadherin expression in pol $\beta \_K O$ A2780 and A2780cis cells compared to control. On the other hand, N-cadherin and MMP-9 were significantly reduced in A2780 pol $\beta \_K O$ cells (Supplementary Fig. S7B-D). TGF $\beta$ was significantly reduced in A2780cis pol $\beta$ KO cells. Supplementary Fig. S7B-D. The data provide evidence that pol $\beta$ may have a role in EMT. To provide additional evidence we performed real-time PCR using $\mathrm{RT}^{2}$ Profiler EMT PCR Array for 86 EMT genes. Full list of EMT genes included in the PCR array is summarised in Supplementary Table S3. Compared to control cells, downregulation of several genes with defined roles in EMT was evident in pol $\beta$ KO cells (Supplementary Fig. S8A, B). Interestingly, we also observed upregulation of some genes with roles in EMT (Supplementary Fig. S8A, B). Together the data would imply a complex role for pol $\beta$ is influencing the expression of genes involved in EMT.

\section{Pol $\beta$ blockade is synthetically lethal in BRCA2 deficient cells}

BRCA2 is a key player in homologous recombination (HR). Patients with germ-line mutations in BRCA2 are predisposed to ovarian cancer development with a cumulative life time risk of about 20-30\% [23]. PARP inhibitor maintenance therapy improves PFS in BRCA2 germ-line deficient ovarian cancers [1-3]. However, not all patients respond either due to intrinsic resistance or acquired resistance to PARP inhibitors [4]. We hypothesised that pol $\beta$ could be a promising alternative synthetic lethality target in BRCA2 deficient ovarian cancers. Pol $\beta$ deficiency impairs BER and leads to accumulation of single-strand breaks, which if unrepaired, result in generation of DSBs during replication. In cells deficient in HR repair (HRR), DSBs would persist and lead to synthetic lethality. We therefore tested synthetic lethality in BRCA2-deficient (PEO1) and BRCA2-proficient (PEO4) ovarian cancer cells. PEO1 and PEO4 cells have robust Pol $\beta$ expression (Fig. 3H) and
(Supplementary Fig. S9A). Cell viability, as investigated by clonogenic assay, was significantly impaired when pol $\beta$ was depleted in PEO1 cells, but not in PEO4 cells (Fig. 3I). Pol $\beta$ depletion in PEO1 cells resulted in increased $\gamma \mathrm{H} 2 \mathrm{AX}$ foci accumulation (Fig. 3J-L) 53BP1 foci accumulation (Fig. 3M), S-phase cell cycle arrest (Fig. 3N) and induction of apoptosis (Fig. 3O). We then tested cytotoxicity of pol $\beta$ inhibitors (pol $\beta \mathrm{i}$ ) in BRCA2-proficient and deficient cell lines. Pamoic acid is a well described pol $\beta$ i [24]. The cytotoxicity of Pamoic acid was first tested in control and pol $\beta \_K O$ cells. We did not observe any significant cytotoxicity in pol $\beta \_K O$ cells compared to control cells (Supplementary Fig. S9B). The data suggest that Pamoic acid may have specific activity against pol $\beta$. Compared to PEO4 cells, PEO1 cells were sensitive to Pamoic acid treatment (Fig. 4A) which was associated with DSB accumulation (Fig. 4B), S-phase arrest (Fig. 4C) and apoptosis (Fig. 4D). We then validated Pamoic acid activity in BRCA2 deficient and control HeLa cells (Fig. 4E). As shown in Fig. 4F, Pamoic acid was selectively toxic in HeLa BRCA2-deficient cells compared to control HeLa cells. Increased sensitivity was associated with DSB accumulation (Fig. 4G), S-phase arrest (Fig. 4H) and increased apoptotic cells (Fig. 4I).

To recapitulate an in vivo system, we then generated 3Dspheroids of PEO1, PEO4, HeLa control and HeLa BRCA2_KD cells (Fig. 4J, K). BRCA2-proficient cells (PEO4 and HeLa controls) and BRCA2-deficient cells (PEO1 and HeLa BRCA2_KD cells) retain spheroid forming capacity (Fig. 4J, K). However, upon Pamoic acid treatment, in BRCA2-deficient spheroids, there was an accumulation of apoptotic cells (Fig. 4L) as well as a reduction in spheroid size (Fig. 4M) compared to BRCA2proficient spheroids (Fig. 4L, M). We then validated using NSC666719 [4-chloro-5-methyl-N-[5-(naphthalen-2-ylamino)-1H1,2,4-triazol-3-yl]-2 sulfanylbenzenesulfonamide], another specific pol $\beta \mathrm{i}$ [25-27]. In BRCA2 deficient spheroids, NSC666719 treatment reduced spheroid size and viability (Fig. 4J-M). NSC666719 treatment also resulted in DSB accumulation (Supplementary Fig. S9C), G2/M cell cycle arrest (Supplementary Fig. S9D) and apoptotic cells (Supplementary Fig. S9E) in BRCA2-deficient cells compared to BRCA2-proficient cells.

\section{PARG inhibitor (PARGi) is selectively toxic in pol $\beta$ deficient cells}

At sites of DNA damage, PARP1 is recruited where it induces the synthesis of poly(ADP-ribose) (PAR). PARylation of PARP1 and other DNA repair factors is essential for coordination of DNA repair [28]. PARylation is transient and reversible process. PAR glycohydrolase (PARG) is a key factor in the PAR degradation pathway [29-31] 

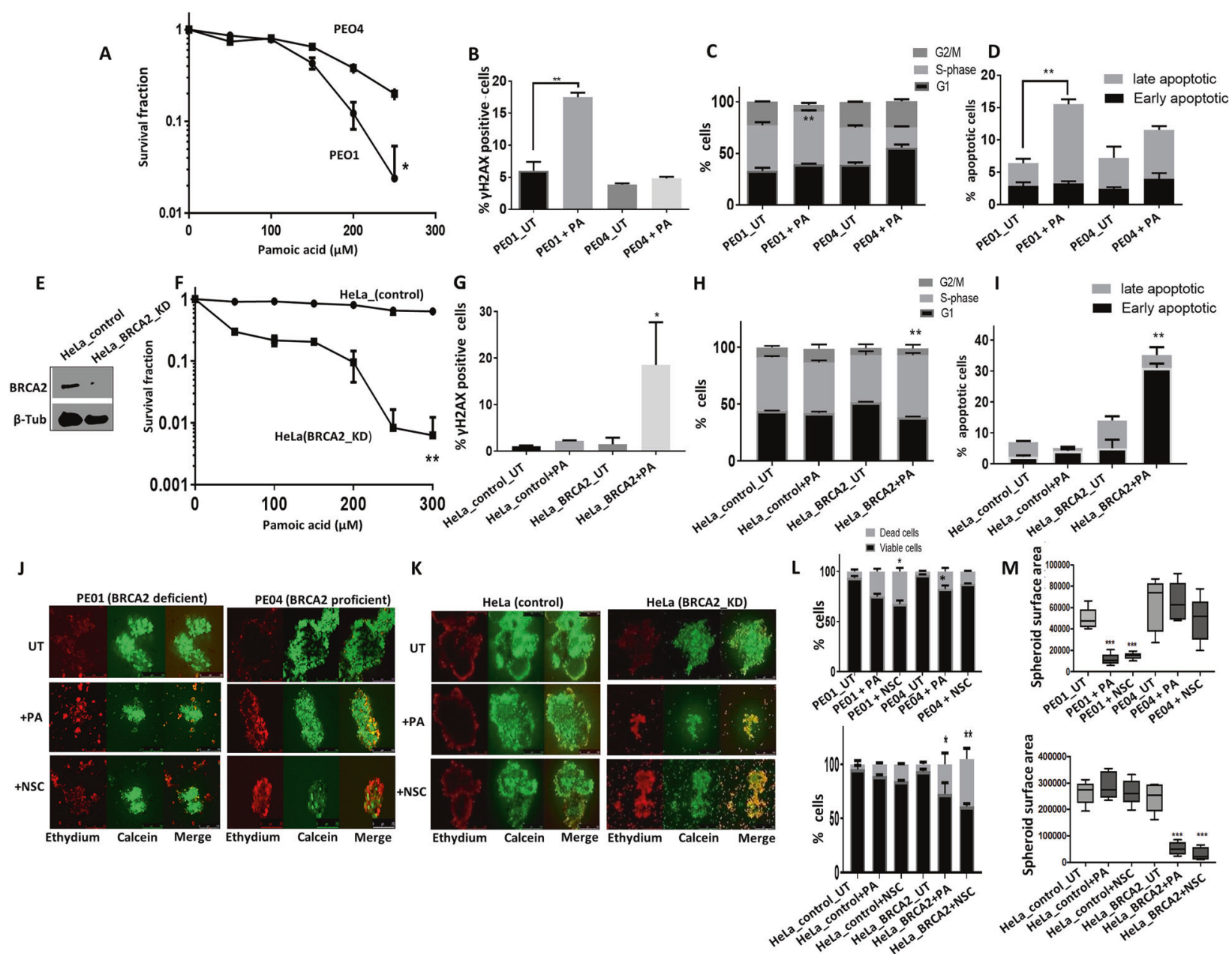

Fig. 4 Pol $\beta$ inhibitors induce synthetic lethality in BRCA2 deficient ovarian cancer cells. A Pamoic acid sensitivity by clonogenic survival assay in PEO1 and PEO4 cells. B $\gamma \mathrm{H} 2 \mathrm{AX}$ analysis by flow cytometry for PEO1 and PEO4 cells treated with Pamoic acid (250â€ $\% \circ \mu \mathrm{M})$. C Cell cycle analysis by flow cytometry in PEO1 and PEO4

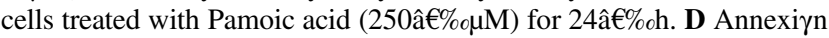
$\mathrm{V}$ analysis by flow cytometry in PEO1 and PEO4 cells treated with Pamoic acid $(250 \hat{a} € \% \circ \mu \mathrm{M})$ for $24 \hat{\mathrm{a}} € \%$ oh. E BRCA2 western blot in HeLa control and HeLa BRCA2_knockdown cells. F Pamoic acid sensitivity in HeLa control and HeLa BRCA2_knock down cells by clonogenic survival assay is shown here. $\gamma \mathrm{H} 2 \mathrm{AX}$ analysis by flow

A coordinated activity of PARP and PARG is also essential for efficient DNA repair. Recently, PARG has also emerged as a promising drug target in cancer [32, 33]. Importantly, a recent study by Pillai et al. demonstrated that ovarian cancer cells respond differently to PARGi (PDD00017273) compared to PARPi (Olaparib) [34]. DNA replication vulnerabilities was shown to particularly render ovarian cancer cells sensitive to PDD00017273 treatment leading to persistent replication fork stalling and replication catastrophe in that study [34]. As pol $\beta$-deficient ovarian cancer cells are not only sensitive to platinum treatment but also show features of replication stress as evidenced by accumulation of ATR and pChk1 $1^{\text {ser } 345}$, we tested a synthetic lethality cytometry $(\mathbf{G})$, cell cycle analysis by flow cytometry $(\mathbf{H})$ and annexinV analysis by flow cytometry (I) in HeLa control and HeLa BRCA2_knockdown cells treated with Pamoic acid $(250 \hat{\mathrm{e}} € \%$ oMM) for 24â€\%oh. Representative photomicrographic images of Pamoic acid $(250 \hat{\mathrm{a}} \% \% \mu \mathrm{M})$ and NSC666719 $(250 \hat{\mathrm{a}} \% \% \mu \mathrm{M})$ treated 3D-spheres of: PEO1 and PEO4 cells (J), HeLa control and HeLa (BRCA2_KD) (K). L Quantification of spheroids cell viability by flow cytometry. M Quantification of spheroids size by ImageJ. Figures are representative of three or more experiments. Error bars represent standard deviation between experiments.

application for either PARPi or PARGi. We first evaluated cellular activity of Olaparib and PDD00017273 in pol $\beta$-deficient and -proficient ovarian cancer cells. Olaparib did not induce selective cytotoxicity in pol $\beta \_K O$ or control cells (Supplementary Fig. S9F, G). However, as shown in Fig. 5A, B, PDD00017273 treatment was selectively toxic in pol $\beta \_$KO A2780 or pol $\beta \_K O ~ A 2780$ cis cells compared to controls. To also validate this observation in PEO4 ovarian cancer cell line, we generated transient knockdown of $\operatorname{pol} \beta$ and again observed increased sensitivity to PDD00017273 treatment in PEO4 cells (Supplementary Fig. S9H). We proceeded to functional studies to understand potential mechanisms of PDD00017273 toxicity. 


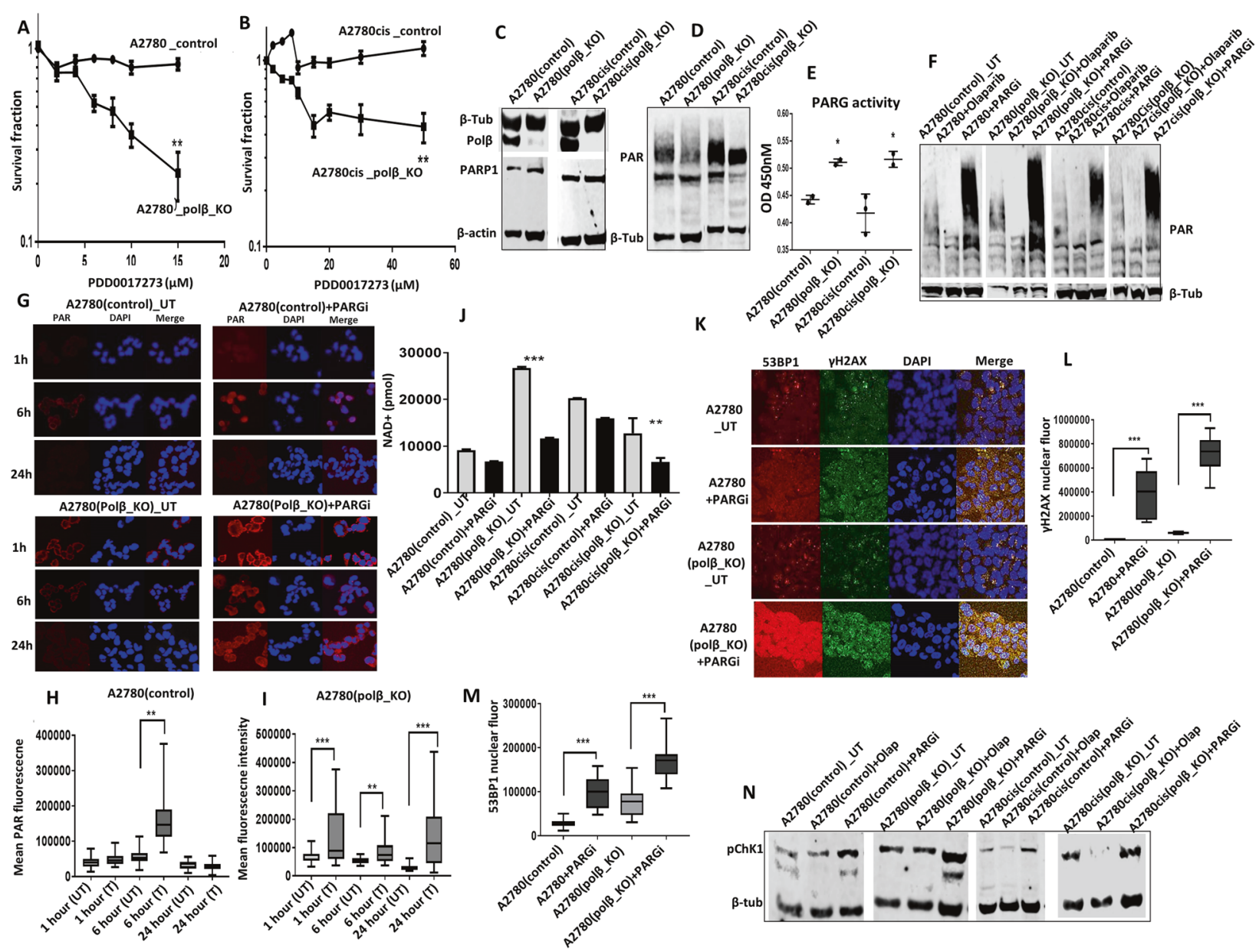

Fig. 5 Polß knock out cells is sensitive to PARG inhibitor. A PARG inhibitor sensitivity by clonogenic survival assay in A2780 control and Pol $\beta$ _knock out cells. B PARG inhibitor sensitivity by clonogenic survival assay in A2780cis control and Pol $\beta \_k n o c k$ out cells. C Pol $\beta$, PARP1 levels by western blot in A2780 and A2780cis control and Pol $\beta$ knockout cells. D Poly (ADP) ribose polymers levels in A2780 and A2780cis control and Pol $\beta$ knock out cells. E PARG ELISA assay in A2780 control, A2780 (Pol $\beta$ KO), A2780cis control and A2780cis (Pol $\left.\beta \_K O\right)$ cells. F Poly (ADP) ribose polymers levels in A2780 and A2780cis control and Pol $\beta$ _knock out cells treated with Olaparib or PARG inhibitor. Cells were treated with Olaparib $(10 \mu \mathrm{M})$ or PARGi $(20 \mu \mathrm{M})$ for $16 \mathrm{~h}$ then extracted for western blot. G Immunofluorescence staining for poly (ADP) ribose polymers in

\section{Mechanistic studies of PARGi in polß-deficient cells}

At baseline, there were no changes in PARP1 levels in both control and pol $\beta$ KO cells (Fig. 5C, Supplementary Figs. S9I, S10A). However, in pol $\beta$ KO cells there was a reduction in PAR level compared to control cells (Fig. 5D) and (Supplementary Fig. S11B, C). Using PARG ELISA assay we show that pol $\beta$ KO cells have increased PARG activity compared to control cells (Fig. 5E). We then evaluated PAR level in pol $\beta$ KO and controls treated with either Olaparib or PDD00017273 (Fig. 5F) and (Supplementary Fig. S10D, E). In Olaparib-treated cells, as
A2780 control and Pol $\beta$ _knockout cells untreated or treated with PARGi $(20 \mu \mathrm{M})$ for 1,6 , and $24 \mathrm{~h}$. H, I Quantification of Poly (ADP) ribose polymers fluorescence by imageJ software. J Quantification of NAD+ levels in A2780 and A2780cis control and Pol $\beta$ _knock out cells. K Representative photomicrographic images of 53BP1 and $\gamma \mathrm{H} 2 \mathrm{AX}$ immunofluorescence in A2780 and A2780cis control and Pol $\beta$ knock out cells treated with PARGi $(20 \mu \mathrm{M})$ for $16 \mathrm{~h}$. L Quantification of $\gamma \mathrm{H} 2 \mathrm{AX}$ nuclear fluorescence by ImageJ software. M Quantification of 53BP1 nuclear fluorescence by ImageJ software. $\mathbf{N}$ p-CHK1 levels by western blot in A2780 and A2780cis control and Pol $\beta$ knock out treated with Olaparib $(10 \mu \mathrm{M})$ or PARGi $(20 \mu \mathrm{M})$ for $16 \mathrm{~h}$. Figures are representative of three or more experiments. Error bars represent standard deviation between experiments.

expected, there was a reduction in PAR levels in both control and pol $\beta$ KO cells which also confirmed in a PAR ELISA assay (Supplementary Fig. S10G). PDD00017273 treatment increased PAR level in control and pol $\beta$ KO cells (Fig. 5F) and (Supplementary Fig. S10D-F). To further validate, we monitored PAR level by confocal microscopy at 1,6 , and $24 \mathrm{~h}$ following PDD00017273 treatment in A2780_ pol $\beta$ KO and control cells (Fig. 5G-I). In A2780 control cells, following PDD00017273 treatment, there was transient increase in PAR accumulation at $6 \mathrm{~h}$ which returned to baseline levels at $24 \mathrm{~h}$ compared to untreated cells. However, in A2780_ pol $\beta \_$KO cells, there 
was accumulation of PAR at $24 \mathrm{~h}$ compared to untreated cells (Fig. 5G-I). PARP1 catalyses the polymerisation of ADP-ribose units (PAR) from NAD+. On the other hand, PARG catalyses the hydrolysis of PAR producing free mono- and oligo(ADP-ribose) [28]. We evaluated NAD+ levels in untreated as well as PDD00017273-treated control and pol $\beta \_$KO cells (Fig. 5J). In untreated A2780_ pol $\beta \_K O$ cells, there was a significant increase in NAD+ levels compared to control cells. Upon PDD00017273 treatment there was a significant reduction in NAD+ levels in A2780_ pol $\beta_{-}$KO cells compared to controls. Interestingly in untreated A2780cis_ pol $\beta$ KO cells, there was no increase in NAD+ levels compared to controls. However following PDD00017273 treatment NAD+ levels significantly reduced compared to controls (Fig. 5J). Together, the data suggest a complex cell line dependent network operating between pol $\beta$, PAR and $\mathrm{NAD}+$. Previous studies have shown that PAR accumulation can not only impair efficient DNA repair but can also be directly toxic to cells $[35,36]$. Depletion of $\mathrm{NAD}+$ is known to alter NAD+/SIRT1 axis which also leads to impaired DNA repair and cell survival [37, 38]. PDD00017273 treatment in A2780_polß_KO cells promoted $\gamma \mathrm{H} 2 \mathrm{AX}$ nuclear foci accumulation (Fig. $5 \mathrm{~K}, \mathrm{~L}$ ) and (Supplementary Fig. S11G), an indirect biomarker for DSBs and replication stress-induced defects. As a further validation of DSBs, we also observed 53BP1 nuclear foci accumulation in PDD00017273-treated A2780_pol $\beta$ _KO cells (Fig. 5K, M). Consistent with PDD00017273 induced replication arrest, CHK1 was phosphorylated on serine 345 in PARGi-treated pol $\beta$ deficient cells (Fig. $5 \mathrm{~N}$, Supplementary Fig. S10H), which was then associated with S-phase arrest (Fig. 6A) and induction of apoptosis (Fig. 6B). Similarly, in A2780cis_ polß_KO cells compared to controls, PDD00017273 treatment was associated with $\gamma \mathrm{H} 2 \mathrm{AX}$ nuclear foci accumulation (Fig. 6C, D), 53BP1 nuclear foci accumulation (Fig. 6E), increased phosphorylated CHK1 (Fig. 5M, Supplementary Fig. S10H), S-phase arrest (Fig. 6F) and apoptosis (Fig. 6G). In 3-D spheroid models, PDD00017273 treatment reduced spheroid size and promoted cell death in pol $\beta \_\mathrm{KO}$ spheroids compared to control spheroids (Fig. 6H-J). Olaparib did not influence cell viability in 3-D spheroid assays (Fig. 6H-J). Together the data suggest that PARGi in pol $\beta$ deficient induces selective cytotoxicity through replication stress, DSB accumulation and cell death. Talazoparib, has at least 100 times more potency to trap PARP at replication forks compared to Olaparib [28]. As expected, A2780_pol $\beta \_K O$ and A2780cis_polB_KO cells were sensitive to Talazoparib therapy compared to controls (Supplementary Fig. S11A, B). The data would suggest that replication stress induction contributes to the observed cytotoxicity.

\section{Clinicopathological significance of PARG expression in human ovarian cancers}

PARG expression was cytoplasmic. Low PARG expression was seen in 60/274 (22\%) tumours and high PARG expression was observed in 214/274 (72\%) of tumours. High PARG expression was associated with serous cystadenocarcinomas $(p=0.011)$ (Supplementary Table S4). PARG expression did not influence PFS (Supplementary Fig. S12A). However, high PARG expression was associated with poor OS in the whole cohort $(p=0.032)$ (Supplementary Fig. S12B). The data suggest that PARG may have prognostic significance in ovarian cancers. We then performed pol $\beta / P A R G$ co-expression analysis. Pol $\beta / P A R G$ coexpression was associated with serous cystadenocarcinomas $(p=0.017)$ and higher stage $(p=0.004)$ (Supplementary Table S5). Tumours with high pol//PARG co-expression have poor PFS (Fig. 6K) $(p=0.041)$ as well as OS (Fig. 6L) $(p=0.045)$ compared to tumours with low polp/PARG coexpression. In multivariate analyses (Supplementary Table S6), $\operatorname{pol} \beta(p=0.012)$ and platinum sensitivity $(0.0001)$ independently influenced PFS. Platinum sensitivity remained independently linked to OS $(p=0.0001)$ (Supplementary Table S6). PARG expression was borderline non-significant in multivariate analysis $(p=0.051$ and 0.056 respectively) (Supplementary Table S6).

\section{Discussion}

Pol $\beta$, a member of the X-family of DNA polymerases is a key player in BER [10]. Pre-clinically we demonstrated that $\operatorname{pol} \beta$ depletion increased platinum sensitivity in platinum resistant A2780cis, PEO4 and PEO1R ovarian cancer cells. In platinum sensitive A2780 cells, although there were some variations due to different experimental conditions, Pol $\beta$ depletion using multiple siRNA constructs consistently increased platinum sensitivity. Interestingly, in cisplatin untreated A2780cis cells pol $\beta$ deficiency caused S-phase arrest and a replication arrest phenotype. However, we did not observe this phenomenon in A2780 or PEO4 cells, implying a cell line dependent role for pol $\beta$ during replication in ovarian cancer cells.

Higher levels of pol $\beta$ have been described in colonic and prostate compared with normal tissue [39, 40]. Mutations in pol $\beta$ may influence aggressive solid tumour phenotype and response to chemotherapy [13]. In ovarian cancers, mutations in pol $\beta$ have been recognised [41] although clinical significance remains unclear [41]. In clinical cohorts of ovarian cancers, we show that low $\operatorname{Pol} \beta$ expression is associated with better PFS. In the current study, we did not observe any cytoplasmic staining for pol $\beta$ protein in ovarian tumours. For nuclear expression, we have observed some 


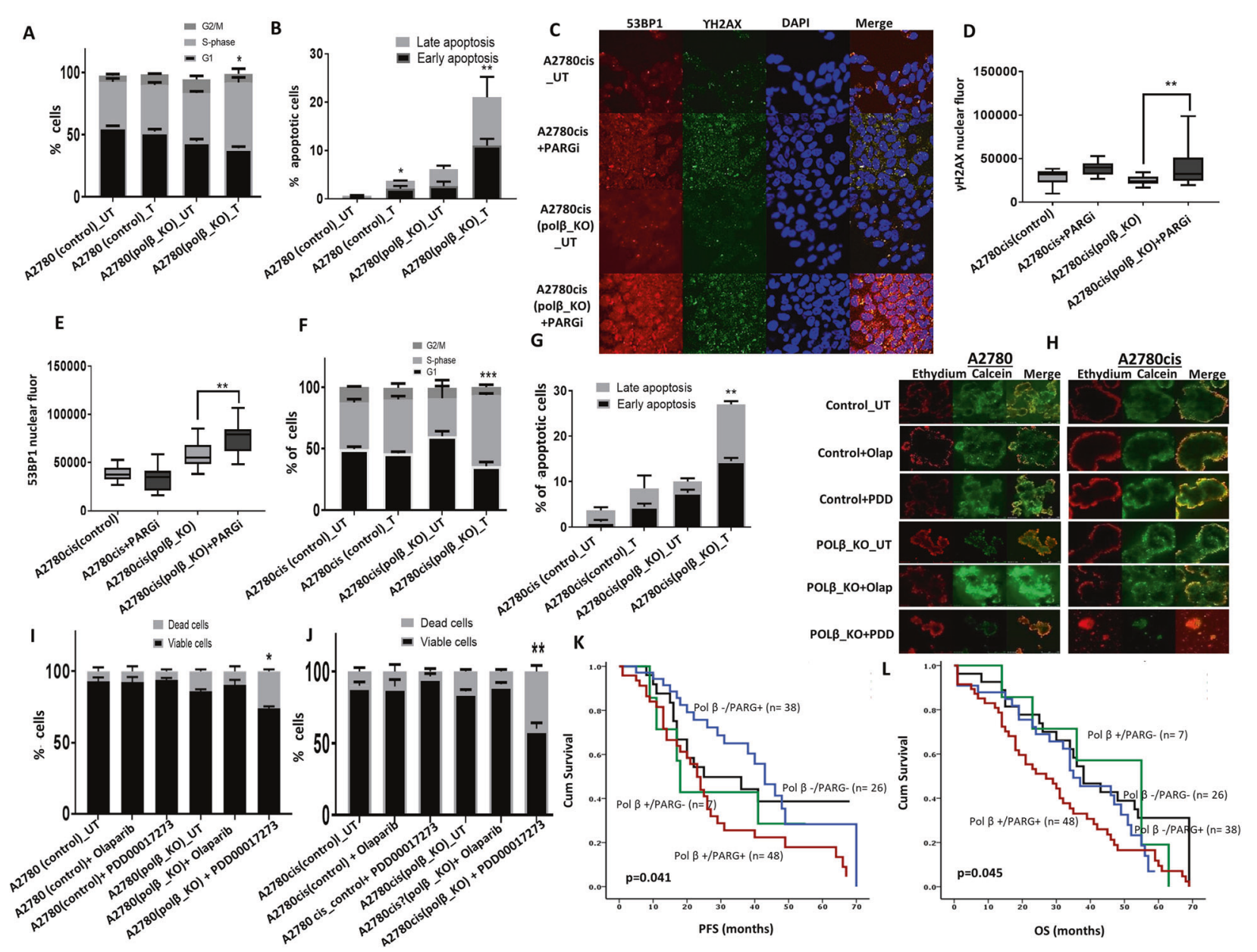

Fig. 6 Mechanisitc studies of PARG inhibitor in ovarian cancer. A Cell cycle analysis by flow cytometry. B Annexin V analysis by flow cytometry for A2780 cells control and Pol $\beta$ _knockout cells treated with $20 \mu \mathrm{M}$ PARGi for $24 \mathrm{~h}$. C Representative photomicrographic images for 53BP1 and $\gamma \mathrm{H} 2 \mathrm{AX}$ immunofluorescence staining in A2780 control and Pol $\beta$ knockout cells treated with $20 \mu \mathrm{M}$ PARGi. D Quantification by $\gamma \mathrm{H} 2 \mathrm{AX}$ nuclear fluorescence by ImageJ software. E Quantification of 53BP1 nuclear fluorescence by ImageJ software. F Cell cycle analysis by flow cytometry. G Annexin V analysis by flow cytometry. A2780cis cells control and Pol $\beta$ knockout cells were treated with $20 \mu \mathrm{M}$ PARGi

peri-nuclear or annular staining for pol $\beta$. Whether this represents altered pol $\beta$ expression or variable pol $\beta$ expression due to DNA damage is unknown but will be an interesting area for further exploration in the future. Importantly, we provide evidence that low pol $\beta$ expression at the protein as well as at the mRNA levels is linked with better PFS.

Pol $\beta$ deficiency in mice is embryonically lethal [42] and embryonic fibroblasts derived from such mice are hypersensitive to alkylating agents [43]. Depletion of $\operatorname{pol} \beta$ delayed the repair of oxaliplatin-induced DNA damage and increased sensitivity in colorectal cancer cell lines [44]. On the other hand, $\operatorname{pol} \beta$ overexpression increased resistance to DNA-damaging agents [45]. Our data concur with a previous study in colorectal cell lines showing platinum sensitivity with pol $\beta$ depletion [46].

for $24 \mathrm{~h}$ cells were collected and analysed as per the flow cytometry protocol or cells were seeded on coverslips and treated with PARGi $(20 \mu \mathrm{M})$ for $24 \mathrm{~h}$ before staining for immunofluorescence protocol. H Representative photomicrographic images for A2780 control and Pol $\beta$ knockout spheroids treated with Olaparib $(10 \mu \mathrm{M})$ or PARGi $(20 \mu \mathrm{M})$. I, J Quantification of spheroids cell viability is shown here. Figures are representative of three or more independent experiments. $\mathbf{K}$ Pol $\beta$ and PARG co-expression and Kaplan-Meier curve for ovarian cancer progression-free survival (PFS). L Pol $\beta$ and PARG co-expression and Kaplan-Meier curve for overall survival in ovarian cancer.

Chronic platinum exposure can alter function of microtubules and microfilaments and can reduce migration [47, 48], a feature also seen in A2780cis cells. We show that wild-type cells have expression of N-Cadherin, TGF $\beta$. and MMP9. Pol $\beta$ depletion reduced N-Cadherin, TGF $\beta$, and MMP9 levels along with induction of E-cadherin. Cadherin switch is the hallmark of EMT [49]. TGF $\beta$ and MMP-9 also have a role migration/invasion [49]. Whilst downregulation of several EMT genes was also evident in pol $\beta$-depleted cells, we speculate an indirect role for $\operatorname{pol} \beta$ in EMT which require future mechanistic study confirmation. Interestingly, previous studies show PARP1 depletion [50] and Histone H2AX depletion [51] in promoting EMT through transcriptional regulation suggesting a complex role for DNA repair in EMT. 
In the current study we not only observed increased nuclear localisation of pol $\beta$ following cisplatin treatment but basal levels of pol $\beta$ protein also appears to be higher in platinum resistant cells. Although we did not identify any activating mutations of $p o l \beta$, we speculate that post transcriptional or translational mechanisms could result in overexpression of pol $\beta$. Another interesting observation was that despite the lack of pol $\beta$ variants, bioinformatics analyses revealed several key pol $\beta$-interacting proteins harboured novel non-synonymous variants, affecting the LIG3, WRN and XRCC3 loci. However, a limitation to the current study is that further detailed functional and mechanistic studies would be required to fully evaluate if pol $\beta$ functional interactome may contribute to platinum resistance in ovarian cancer cells.

We show that pol $\beta$ i can induce synthetic lethality in BRCA2-deficient cells. Although promising, future in vivo xenograft studies are required to confirm our findings. PARG blockade is also selectively toxic in pol $\beta$-deficient cells. Pol $\beta$ depletion or inhibition increase SSBs. PARG is essential for efficiency of SSB repair [52]. In pol $\beta$ deficient cells we observed increased PARG activity. PARG inhibition or depletion can also increase reversed replication forks and post-replicative single-strand breaks $[32,33]$. In pol $\beta$ deficient cells with impaired BER and increased SSB, PARG inhibition leads to profound accumulation of SSBs which get converted to DSB leading to synthetic lethality. Accordingly, we observed DSB accumulation, S-phase arrest and apoptosis in PDP00017273-treated pol $\beta$-deficient cells compared to -proficient cells. Additionally, PARG inhibition was associated with accumulation of PAR polymers in pol $\beta$-deficient cells. Accumulation of PAR was accompanied by NAD+ depletion via two potential mechanisms; (1) PARP uses NAD+ as ADP-ribose donor and catalyse PARylation of target proteins including itself. 2) PARG mediates rapid turnover of PAR to mono-ADP-ribose units which is recycled as the ATP precursor, an important substrate to generate $\mathrm{NAD}+$. PARGi will therefore increase $\mathrm{NAD}+$ [31]. PARG mediated reversal of auto-modification of DNA bound PARP1 leads to poly-ubiquitination of PARP1 by the E3 ligase CHFR. Removal and degradation of PARP1 contribute further to the restoration of NAD+ levels. In PARGi-treated cells, therefore, reduced level of $\mathrm{NAD}+$ may persists [53]. There are at least two mechanisms for NAD+ depletion induced cell death; (1) caspaseindependent programmed necrosis, where excess PAR activates apoptosis-inducing factor, which triggers the apoptotic cascade [35, 36]. (2) NAD+ depletion can alter Sirtuin level and impair BER [37, 38] contributing further to SSB accumulation. Moreover, PAR accumulation is also known to be toxic to cells and can also impair DNA repair [35]. However, it should be noted that persistent accumulation of PAR polymers in A2780 Pol $\beta$ KO cells but transient formation of PAR polymers in the control A2780 was observed in the current study. The exact molecular mechanisms of this phenomenon are not clear although an increased level of PAR formation is expected with inhibition of PARG (which hydrolyses PAR polymers). As described, PAR accumulation and NAD depletion can contribute directly and indirectly to the impairment of DNA machinery, which could be more lethal in the context of $\operatorname{pol} \beta$ deficiency [54, 55]. A recent study proposed that loss of PARG activity is a possible mechanism for PARPi resistance in BRCA2 deficient tumours. PARG operates in the same direction as PARPi by preventing PAR accumulation. Hence, decreased PARG activity can allow tumour cells to escape the PARPi mediated synthetic lethality [29]. These findings concur with our observations in pol $\beta$ deficient ovarian cancer cells. Another study by Pillay et al. has revealed that ovarian cancer cells respond differently to PARGi (PDD00017273) compared to PARP inhibitor (Olaparib) and may be dependent on DNA replication vulnerabilities in cells [34]. Therefore endogenous PARG levels could predict Olaparib response in HR deficient as well as in pol $\beta$ deficient ovarian cancer cells. PARGi is also synthetically lethal in BRCA1 [32], BRCA2, PALB2, FAM175A and BARD1 deficient breast cancer cells [33].

In conclusion, pol $\beta$ blockade is a novel approach warrants for development in ovarian cancers.

\section{Materials and methods}

Full details are available in Supplementary material and methods.

\section{Clinical study}

Pol $\beta$ immunohistochemistry was completed in 525 epithelial ovarian cancers. Pol $\beta$ mRNA expression in human epithelial ovarian was investigated in three ovarian tumour gene expression data sets [test set, validation cohort 1 and validation cohort 2 (TCGA). See Supplementary methods for full details. Ethical approval which was obtained from the Nottingham Research Ethics Committee (REC Approval Number 06/Q240/153). All patients provided informed consent.

\section{Pre-clinical study}

A2780, A2780cis, PEO1 and PEO4 were purchased from American Type Culture Collection (ATCC, Manassas, USA). BRCA2-deficient HeLa SilenciX cells and controls BRCA2-proficient HeLa SilenciX cells were purchased from Tebu-Bio (www.tebu-bio.com).

Methodology for transient knockdown of $\operatorname{Pol} \beta$ and generation of Pol $\beta$ knockouts are described in Supplementary methods. 
Compounds, reagents, clonogenic assays, cell proliferation assays, confocal microscopy, functional assays (FACS, cell cycle progression, apoptosis assays. ELISA), invasion assay, migration assay, 3D-spheroid assays, next generation sequencing and bioinformatics are described in Supplementary methods.

Acknowledgements Research in Madhusudan lab is supported by Naaz-Coker Ovarian Cancer Fellowship, University of Nottingham, UK.

\section{Compliance with ethical standards}

Conflict of interest The authors declare no competing interests.

Publisher's note Springer Nature remains neutral with regard to jurisdictional claims in published maps and institutional affiliations.

Open Access This article is licensed under a Creative Commons Attribution 4.0 International License, which permits use, sharing, adaptation, distribution and reproduction in any medium or format, as long as you give appropriate credit to the original author(s) and the source, provide a link to the Creative Commons license, and indicate if changes were made. The images or other third party material in this article are included in the article's Creative Commons license, unless indicated otherwise in a credit line to the material. If material is not included in the article's Creative Commons license and your intended use is not permitted by statutory regulation or exceeds the permitted use, you will need to obtain permission directly from the copyright holder. To view a copy of this license, visit http://creativecommons. org/licenses/by/4.0/.

\section{References}

1. Moore K, Colombo N, Scambia G, Kim BG, Oaknin A, Friedlander M. et al. Maintenance olaparib in patients with newly diagnosed advanced ovarian cancer. N Engl J Med. 2018;379:2495-505.

2. Mirza MR, Monk BJ, Herrstedt J, Oza AM, Mahner S, Redondo A, et al. Niraparib maintenance therapy in platinum-sensitive, recurrent ovarian cancer. N. Engl J Med. 2016;375:2154-64.

3. Swisher EM, Lin KK, Oza AM, Scott CL, Giordano H, Sun J, et al. Rucaparib in relapsed, platinum-sensitive high-grade ovarian carcinoma (ARIEL2 Part 1): an international, multicentre, openlabel, phase 2 trial. Lancet Oncol. 2017;18:75-87.

4. D'Andrea AD. Mechanisms of PARP inhibitor sensitivity and resistance. DNA Repair. 2018;7:172-6.

5. Lindahl T. Repair of intrinsic DNA lesions. Mutat Res. 1990;238:305-11.

6. Dianov G, Bischoff C, Piotrowski J, Bohr VA. Repair pathways for processing of 8-oxoguanine in DNA by mammalian cell extracts. J Biol Chem. 1998;273:33811-6.

7. Frosina G, Fortini P, Rossi O, Carrozzino F, Raspaglio G, Cox LS, et al. Two pathways for base excision repair in mammalian cells. J Biol Chem. 1996;271:9573-8.

8. Matsumoto Y, Kim K. Excision of deoxyribose phosphate residues by DNA polymerase beta during DNA repair. Science. 1995;269:699-702.

9. Dianov G, Lindahl T. Reconstitution of the DNA base excisionrepair pathway. Curr Biol. 1994;4:1069-76.

10. Dianov GL, Hubscher U. Mammalian base excision repair: the forgotten archangel. Nucleic Acids Res. 2013;41:3483-90.

11. Sweasy JB. Fidelity mechanisms of DNA polymerase beta. Prog Nucleic Acid Res Mol Biol. 2003;73:137-69.
12. Beaufort CM, Helmijr JC, Piskorz AM, Hoogstraat M, RuigrokRitstier K, Besselink N, et al. Ovarian cancer cell line panel (OCCP): clinical importance of in vitro morphological subtypes. PLoS ONE. 2014;9:e103988.

13. Starcevic D, Dalal S, Sweasy JB. Is there a link between DNA polymerase beta and cancer? Cell Cycle. 2004;3:998-1001.

14. McLaren W, Gil L, Hunt SE, Riat HS, Ritchie GR, Thormann A, et al. The Ensembl Variant Effect Predictor. Genome Biol. 2016;17:122.

15. Oughtred R, Stark C, Breitkreutz BJ, Rust J, Boucher L, Chang C, et al. The BioGRID interaction database: 2019 update. Nucleic Acids Res. 2019;47:D529-41.

16. Parlanti E, Locatelli G, Maga G, Dogliotti E. Human base excision repair complex is physically associated to DNA replication and cell cycle regulatory proteins. Nucleic Acids Res. 2007;35:1569-77.

17. Delfini C, Alfani E, De Venezia V, Oberholtzer G, Tomasello C, Eremenko T, et al. Cell-cycle dependence and properties of the HeLa cell DNA polymerase system. Proc Natl Acad Sci USA. $1985 ; 82: 2220-4$.

18. Loret N, Denys H, Tummers P, Berx G. The role of epithelial-tomesenchymal plasticity in ovarian cancer progression and therapy resistance. Cancers. 2019;11:838.

19. Wong SHM, Fang CM, Chuah LH, Leong CO, Ngai SC. E-cadherin: Its dysregulation in carcinogenesis and clinical implications. Crit Rev Oncol Hematol. 2018;121:11-22.

20. Blaschuk OW. N-cadherin antagonists as oncology therapeutics. Philos Trans R Soc Lond B Biol Sci. 2015;370:20140039.

21. Moustakas A, Heldin CH. Mechanisms of TGFbeta-induced epithelial-mesenchymal transition. J Clin Med. 2016;5:63.

22. Farina AR, Mackay AR. Gelatinase B/MMP-9 in Tumour Pathogenesis and Progression. Cancers. 2014;6:240-96.

23. Roy R, Chun J, Powell SN. BRCA1 and BRCA2: different roles in a common pathway of genome protection. Nat Rev Cancer. 2011;12:68-78.

24. Hazan C, Boudsocq F, Gervais V, Saurel O, Ciais M, Cazaux C, et al. Structural insights on the pamoic acid and the $8 \mathrm{kDa}$ domain of DNA polymerase beta complex: towards the design of higheraffinity inhibitors. BMC Struct Biol. 2008;8:22.

25. Jaiswal AS, Panda H, Law BK, Sharma J, Jani J, Hromas R, et al. NSC666715 and its analogs inhibit strand-displacement activity of DNA polymerase beta and potentiate temozolomide-induced dna damage, senescence and apoptosis in colorectal cancer cells. PLoS ONE. 2015;10:e0123808.

26. Jaiswal AS, Banerjee S, Aneja R, Sarkar FH, Ostrov DA, Narayan S. DNA polymerase beta as a novel target for chemotherapeutic intervention of colorectal cancer. PLoS ONE. 2011;6:e16691.

27. Jaiswal AS, Banerjee S, Panda H, Bulkin CD, Izumi T, Sarkar FH, et al. A novel inhibitor of DNA polymerase beta enhances the ability of temozolomide to impair the growth of colon cancer cells. Mol Cancer Res. 2009;7:1973-83.

28. Lord CJ, Ashworth A. PARP inhibitors: synthetic lethality in the clinic. Science. 2017;355:1152-8.

29. Gogola E, Duarte AA, de Ruiter JR, Wiegant WW, Schmid JA, de Bruijn R, et al. Selective loss of PARG restores PARylation and counteracts PARP inhibitor-mediated synthetic lethality. Cancer Cell. 2018;33:1078-93.e1012.

30. Koh DW, Dawson VL, Dawson TM. The road to survival goes through PARG. Cell Cycle. 2005;4:397-9.

31. Min W, Wang ZQ. Poly (ADP-ribose) glycohydrolase (PARG) and its therapeutic potential. Front Biosci. 2009;14:1619-26.

32. Fathers C, Drayton RM, Solovieva S, Bryant HE. Inhibition of poly(ADP-ribose) glycohydrolase (PARG) specifically kills BRCA2-deficient tumor cells. Cell Cycle. 2012;11:990-7.

33. Gravells P, Grant E, Smith KM, James DI, Bryant HE. Specific killing of DNA damage-response deficient cells with inhibitors of poly(ADP-ribose) glycohydrolase. DNA Repair. 2017;52:81-91. 
34. Pillay N, Tighe A, Nelson L, Littler S, Coulson-Gilmer C, Bah N, et al. DNA replication vulnerabilities render ovarian cancer cells sensitive to poly(ADP-ribose) glycohydrolase inhibitors. Cancer Cell. 2019;35:519-33.e518.

35. Andrabi SA, Kim NS, Yu SW, Wang H, Koh DW, Sasaki M, et al. Poly(ADP-ribose) (PAR) polymer is a death signal. Proc Natl Acad Sci USA. 2006;103:18308-13.

36. Yu SW, Andrabi SA, Wang H, Kim NS, Poirier GG, Dawson TM, et al. Apoptosis-inducing factor mediates poly(ADP-ribose) (PAR) polymer-induced cell death. Proc Natl Acad Sci USA. 2006;103:18314-9.

37. Lombard DB. Sirtuins at the breaking point: SIRT6 in DNA repair. Aging. 2009;1:12-6.

38. Ying W, Alano CC, Garnier P, Swanson RA. NAD+ as a metabolic link between DNA damage and cell death. J Neurosci Res. 2005;79:216-23.

39. Srivastava DK, Husain I, Arteaga CL, Wilson SH. DNA polymerase beta expression differences in selected human tumors and cell lines. Carcinogenesis. 1999;20:1049-154.

40. Dong ZM, Zheng NG, Wu JL, Li SK, Wang YL. Difference in expression level and localization of DNA polymerase beta among human esophageal cancer focus, adjacent and corresponding normal tissues. Dis Esophagus. 2006;19:172-6.

41. Khanra K, Panda K, Bhattacharya C, Mitra A, Sarkar R, Banerjee $\mathrm{S}$, et al. Association between newly identified variant form of DNA polymerase beta (Delta 208-304) and ovarian cancer. Cancer Biomark. 2012;11:155-60.

42. Gu H, Marth JD, Orban PC, Mossmann H, Rajewsky K. Deletion of a DNA polymerase beta gene segment in $\mathrm{T}$ cells using cell type-specific gene targeting. Science. 1994;265:103-6.

43. Sobol RW, Wilson SH. Mammalian DNA beta-polymerase in base excision repair of alkylation damage. Prog Nucleic Acid Res Mol Biol. 2001;68:57-74.

44. Yang J, Parsons J, Nicolay NH, Caporali S, Harrington CF, Singh $\mathrm{R}$, et al. Cells deficient in the base excision repair protein, DNA polymerase beta, are hypersensitive to oxaliplatin chemotherapy. Oncogene. 2010;29:463-8.

45. Canitrot Y, Cazaux C, Frechet M, Bouayadi K, Lesca C, Salles B, et al. Overexpression of DNA polymerase beta in cell results in a mutator phenotype and a decreased sensitivity to anticancer drugs. Proc Natl Acad Sci USA. 1998;95:12586-90.

46. Iwatsuki M, Mimori K, Yokobori T, Tanaka F, Tahara K, Inoue $\mathrm{H}$, et al. A platinum agent resistance gene, POLB, is a prognostic indicator in colorectal cancer. J Surg Oncol. 2009;100:261-6.

47. Raudenska M, Balvan J, Fojtu M, Gumulec J, Masarik M. Unexpected therapeutic effects of cisplatin. Metallomics. 2019;11:1182-99.

48. Raudenska M, Kratochvilova M, Vicar T, Gumulec J, Balvan J, Polanska H, et al. Cisplatin enhances cell stiffness and decreases invasiveness rate in prostate cancer cells by actin accumulation. Sci Rep. 2019;9:1660.

49. Lamouille S, Xu J, Derynck R. Molecular mechanisms of epithelial-mesenchymal transition. Nat Rev Mol Cell Biol. 2014;15:178-96.

50. Pu H, Horbinski C, Hensley PJ, Matuszak EA, Atkinson T, Kyprianou N. PARP-1 regulates epithelial-mesenchymal transition (EMT) in prostate tumorigenesis. Carcinogenesis. 2014;35:2592-601.

51. Weyemi U, Redon CE, Choudhuri R, Aziz T, Maeda D, Boufraqech $\mathrm{M}$, et al. The histone variant H2A.X is a regulator of the epithelial-mesenchymal transition. Nat Commun. 2016;7:10711.

52. Fisher AE, Hochegger H, Takeda S, Caldecott KW. Poly(ADPribose) polymerase 1 accelerates single-strand break repair in concert with poly(ADP-ribose) glycohydrolase. Mol Cell Biol. 2007;27:5597-605.

53. Pascal JM, Ellenberger T. The rise and fall of poly(ADP-ribose): an enzymatic perspective. DNA Repair. 2015;32:10-6.

54. Croteau DL, Fang EF, Nilsen H, Bohr VA. NAD $(+)$ in DNA repair and mitochondrial maintenance. Cell Cycle. 2017;16:491-2.

55. Fouquerel E, Sobol RW. ARTD1 (PARP1) activation and NAD $(+)$ in DNA repair and cell death. DNA Repair. 2014;23:27-32. 